\title{
PERENCANAAN STRATEGI PT. X DENGAN PENDEKATAN MANAJEMEN STRATEGI
}

\author{
Gusti Adriansyah ${ }^{1}$, Adi Pramono² \\ e-mail : gustiadriansyah@yahoo.com, pramonoadi1987@gmail.com \\ Progam Studi Teknik Industri, Fakultas Teknik, \\ Universitas Maarif Hasyim Latif, Sidoarjo, Indonesia
}

\begin{abstract}
ABSTRAK
PT. X merupakan home industry yang bergerak dibidang pembuatan knalpot di daerah Krian, kabupaten Sidoarjo. Hasil produksi knalpot PT. X ini sangat diminati oleh masyarakat luas, khususnya di wilayah Sidoarjo dan sekitarnya. Meski demikian, produk knalpot di Sidoarjo ini memiliki banyak kompetitor. Saat ini PT. X belum membuat perencanaan strategi dengan baik. Dari hasil survei, diketahui beberapa variabel lingkungan yang mempengaruhi perusahaan, diantaranya adalah lokasi PT. X, kegiatan promosi, jumlah tenaga kerja, dan jenis produk yang dihasilkan. Metode yang digunakan dalam penentuan strategi ini adalah metode analisis SWOT. Dari hasil perhitungan didapatkan nilai tertimbang IFE sebesar 2,75 dan EFE sebesar 2,20. Pada matriks IE menunjukkan posisi Home Industry PT. X berada pada kuadran V. Pada posisi kuadran ini, strategi yang terpilih adalah strategi pertahankan dan pelihara. Sedang pada matriks CPM skor tertinggi sebesar 3,51 merupakan nilai dari pesaing utama PT. X.
\end{abstract}

Kata Kunci : manajemen strategi, matriks SWOT, strategi pertahankan dan pelihara.

\section{PENDAHULUAN}

Industri knalpot merupakan industri yang sedang trend saat kini, dengan model dan kombinasi warna yang menjadi pertimbangan dalam pilihan konsumen. PT. X adalah home industry yang bergerak dibidang pembuatan knalpot di daerah Krian, kabupaten Sidoarjo. Hasil produksi knalpot PT. X ini sangat diminati oleh konsumen pada umumnya, khususnya wilayah Sidoarjo dan sekitarnya.

Akan tetapi PT. X belum mempunyai perencanaan strategi yang baik, dimana beberapa aspek dalam industri knalpot yang dihasilkan belum banyak dipertimbangkan. Di sisi lain, beberapa aspek yang juga cukup mempengaruhi perkembangan perusahaan seperti lokasi, promosi, tenaga kerja, serta variasi produk, masih belum dipertimbangkan dalam perencanaan strategi.

\section{METODE PENELITIAN}

Pada penelitian ini, metode yang dipilih adalah metode SWOT, dengan beberapa pendekatan mengikuti proses dalam manajemen strategi sesuai kebutuhan penelitian. Alur dalam penelitian ini adalah sebagai berikut:

\begin{tabular}{l|l}
\hline Matriks \\
IFE \& EFE
\end{tabular}

Observasi lingkungan internal dan eksternal menggunakan matriks IFE dan EFE untuk mencari aspek kekuatan, kelemahan, peluang, serta ancaman yang dihadapi perusahaan.
Untuk menganalisis strategi, PT. X menggunakan matriks SWOT dan menghasilkan strategi SO, WO, ST, dan WT, yang selanjutnya 
disesuaikan berdasarkan hasil posisi kuadran strategi matriks IE.

Matriks IE dibutuhkan untuk menentukan posisi relatif perusahaan dalam kuadran strategi dimana masing-masing kuadran memiliki strategi tersendiri berdasarkan pertimbangan histori berbagai perusahaan.

Penggunaan Matriks CPM adalah untuk mengidentifikasi nilai skor tertinggi dari pesaing utama PT. X sebagai pertimbangan dalam menentukan target atau tujuan perencanaan strategi, yaitu harus melebihi atau minimal sama dengan skor tertinggi pesaing.

\section{HASIL DAN PEMBAHASAN}

Berikut ini adalah hasil pengolahan data menggunakan pendekatan manajemen strategi dan matriks SWOT.

\section{MATRIKS IFE dan EFE}

Dari observasi kondisi lingkungan internal didapatkan aspek kekuatan dan kelemahan perusahaan, dan dengan menggunakan analisa matriks IFE dapat ditentukan nilai bobot dan rating dari setiap faktor.

Hasil observasi kondisi lingkungan internal perusahaan dapat dijabarkan pada tabel 1 . dibawah ini :

Tabel 1. Kekuatan dan Kelemahan PT. X

\begin{tabular}{|c|l|c|l|}
\hline NO & \multicolumn{1}{|c|}{ KEKUATAN } & NO & \multicolumn{1}{|c|}{ KELEMAHAN } \\
\hline A & Produk dapat diminati & F & $\begin{array}{l}\text { Kurangnya promosi penjualan } \\
\text { produk }\end{array}$ \\
\hline B & Harga terjangkau & G & Kurangnya pasokan dana \\
\hline C & Tempat strategis & H & Kurangnya varian produk \\
\hline D & $\begin{array}{l}\text { Bahan baku mudah di } \\
\text { dapat }\end{array}$ & I & $\begin{array}{l}\text { Kapasitas produk yang } \\
\text { dihasilkanmaasih sedikit }\end{array}$ \\
\hline E & $\begin{array}{l}\text { Pemasangan langsung } \\
\text { ketangan konsumen }\end{array}$ & J & $\begin{array}{l}\text { Belum adanya penelitian } \\
\text { tentang bahan baku bentuk } \\
\text { dan kualitas }\end{array}$ \\
\hline
\end{tabular}

Matriks IFE diperoleh melalui penilaian masing-masing faktor strategis internal PT. X yang responden tentang sejauh mana faktor strategis internal mempengaruhi PT. X. Setiap responden melakukan penilaian bobot dan rating terhadap

Tabel 2. Data Bobot dan Rating IFE

\begin{tabular}{|c|c|c|c|c|}
\hline \multirow{2}{*}{\multicolumn{2}{|c|}{ FAKTOR INTERNAL }} & Bobot & Ranting & Skor \\
\hline & & (a) & (b) & $(a \times b)$ \\
\hline \multicolumn{5}{|c|}{ KEKUATAN } \\
\hline 1 & Produk banyak diminati & 0,15 & 3 & 0,45 \\
\hline 2 & Harga terjangkau & 0,09 & 2 & 0,18 \\
\hline 3 & Tempat strategis & 0,09 & 3 & 0,27 \\
\hline 4 & Bahan baku mudah di dapat & 0,11 & 4 & 0,44 \\
\hline 5 & Pemasaran langsung ketangan konsumen & 0,06 & 4 & 0,24 \\
\hline \multicolumn{5}{|c|}{ KELEMAHAN } \\
\hline 1 & Kurangnya promosi penjualan produk & 0,08 & 3 & 0,24 \\
\hline 2 & Kurangnya pasokan dana & 0,09 & 4 & 0,36 \\
\hline 3 & Kurangnya variasi model produk & 0,11 & 4 & 0,44 \\
\hline 4 & $\begin{array}{l}\text { Kapasitas produk yang dihasilkan masih } \\
\text { sedikit }\end{array}$ & 0,14 & 3 & 0,42 \\
\hline 5 & $\begin{array}{l}\text { Belum adanya penelitian tentangbahan } \\
\text { baku bentuk dan kualitas suara }\end{array}$ & 0,08 & 2 & 0,16 \\
\hline \multicolumn{2}{|r|}{ TOTAL } & $\mathbf{1 , 0 0}$ & & 2,75 \\
\hline
\end{tabular}

Berdasarkan Tabel 2. analisis matriks IFE diatas menghasilkan total nilai tertimbang (skor) sebesar 2.75. Total nilai tertimbang IFE ini mengindikasikan bahwa kemampuan PT. X dalam merespon lingkungan internalnya masih rata-rata. Hasil ini juga menunjukkan bahwa kekuatan utama dari PT. X ini adalah produk yang banyak diminati, dengan nilai tertimbang tertinggi sebesar 0,45 . 
Sedangkan kelemahan utama perusahaan adalah kurangnya variasi model, dengan nilai tertimbang ancaman terbesar sebesar 0,44.
Sedangkan dari hasil observasi lingkungan eksternal perusahaan dapat dijabarkan pada tabel 3. dibawah ini :

Tabel 3. Peluang dan Ancaman PT. X

\begin{tabular}{c|l|c|l}
\hline NO & \multicolumn{1}{|c|}{ PELUANG } & NO & \multicolumn{1}{|c}{ ANCAMAN } \\
\hline A & Daya beli masyarakat semakin tinggi & E & Harga bahan baku terus naik \\
\hline B & $\begin{array}{l}\text { Bertambahnya jumlah penduduk tiap } \\
\text { tiap tahun, membuat peluang semakin } \\
\text { besar }\end{array}$ & F & $\begin{array}{l}\text { Pergantian musim hujan } \\
\text { mempengarjhi hasil produk dan } \\
\text { kualitas produk }\end{array}$ \\
\hline C & Tingkat motif knalpot semakin tinggi & G & $\begin{array}{l}\text { Kemajuan alat modern pembuatan } \\
\text { knalpot }\end{array}$ \\
\hline D & $\begin{array}{l}\text { Pemilik bekerjasama dengan agen } \\
\text { distributor maupun toko peralatan } \\
\text { mobil untuk pemasarannya }\end{array}$ & H & $\begin{array}{l}\text { Keadaan politik sangat m naik } \\
\text { turunnya harga produk empengaruhi }\end{array}$ \\
\hline E & $\begin{array}{l}\text { Masyarakat yang berminat dengan } \\
\text { variasi knalpot }\end{array}$ & I & $\begin{array}{l}\text { Konsumen cenderung lebih } \\
\text { menyukai knal pot modern }\end{array}$ \\
\hline
\end{tabular}

Matriks EFE diperoleh melalui penilaian strategis eksternal berpengaruh terhadap responden mengenai sejauh mana faktor-faktor perusahaan.

Tabel 4. Data Bobot dan Rating EFE

\begin{tabular}{|c|c|c|c|c|}
\hline \multirow{2}{*}{\multicolumn{2}{|c|}{ FAKTOR EKSTERNAL }} & Bobot & Ranting & Skor \\
\hline & & (a) & (b) & (axb) \\
\hline \multicolumn{5}{|c|}{ PELUANG } \\
\hline 1 & Daya beli masyarakat semakin tinggi & 0,24 & 3 & 0,72 \\
\hline 2 & $\begin{array}{l}\text { Bertambahnya jumlah penduduk tiap tahun, membuat } \\
\text { peluang semakin besar }\end{array}$ & 0,20 & 3 & 0,6 \\
\hline 3 & Tingkat motif knalpot semakin tinggi & 0,18 & 4 & 0,72 \\
\hline 4 & $\begin{array}{l}\text { Pemilik bekerjasama dengan agen distributor maupun } \\
\text { toko peralatan mobil untuk pemasarannya }\end{array}$ & 0,21 & 4 & 0,84 \\
\hline 5 & Masyarakat yang berminat dengan variasi knalpot & 0,17 & 2 & 0,42 \\
\hline \multicolumn{2}{|c|}{ TOTAL } & $\mathbf{1 , 0 0}$ & & $\mathbf{3 . 3 0}$ \\
\hline \multicolumn{5}{|c|}{ ANCAMAN } \\
\hline 1 & Harga bahan baku terus naik & 0,17 & 3 & 0,51 \\
\hline 2 & $\begin{array}{l}\text { Disaat musim penghujan pemesaran produk akan } \\
\text { tersedat begitu juga dengan hasil kualitas dari bahan } \\
\text { baku knalpot }\end{array}$ & 0,20 & 4 & 0,8 \\
\hline 3 & $\begin{array}{l}\text { Banyak hasil produk saat ini yang lebih berkualitas } \\
\text { karena pembuatan produk tersebut menggunakan alat } \\
\text { yang lebih modern }\end{array}$ & 0,18 & 3 & 0,54 \\
\hline 4 & $\begin{array}{l}\text { Keadaan politik sangat mempengaruhi naik turunnya } \\
\text { harga produk }\end{array}$ & 0,25 & 3 & 0,75 \\
\hline \multirow[t]{2}{*}{5} & $\begin{array}{l}\text { Konsumen cenderung lebih menyukai hasil produk } \\
\text { knalpot yang di buat secara modern }\end{array}$ & 0,20 & 2 & 0,4 \\
\hline & TOTAL & $\mathbf{1 , 0 0}$ & & 2.20 \\
\hline
\end{tabular}

Berdasarkan Tabel 4 diatas, dilakukan analisis Matriks EFE yang menghasilkan nilai tertimbang (skor) keseluruhan sebesar 2,20 Peluang utama dalam lingkungan eksternal Perusahaan ini ditunjukkan oleh faktor kerjasama pemilik dengan agen distributor dengan nilai tertimbang sebesar 0.85. Sedangkan faktor ancaman utama, ditunjukkan oleh faktor tersendat dan turunnya kualitas bahan baku, terutama saat musim hujan dengan nilai tertimbang yaitu sebesar 0,8

\section{MATRIKS SWOT}

Arti SWOT adalah S untuk Strenghts (kekuatan), W untuk Weakness (kelemahan), 0 untuk Opportunities (peluang), dan T untuk Threats 
(ancaman) dari lingkungan internal dan eksternal perusahaan. "SWOT" merupakan suatu analisa yang baik dalam kegiatan perencanaan atau perumusan strategi perusahaan apabila digunakan pada kondisi yang tepat.

Analisis SWOT adalah salah satu metode yang digunakan untuk menentukan strategi perusahaan dengan mempertimbangkan faktor- faktor yang menjadi kekuatan, kelemahan, peluang, dan ancaman yang terdapat pada perusahaan.

Berdasarkan matriks faktor strategi internal dan eksternal (IFE dan EFE) maka dapat diambil langkah-langkah dari strategi SO, WO, ST, dan WT yang akan diuraikan sebagai berikut:

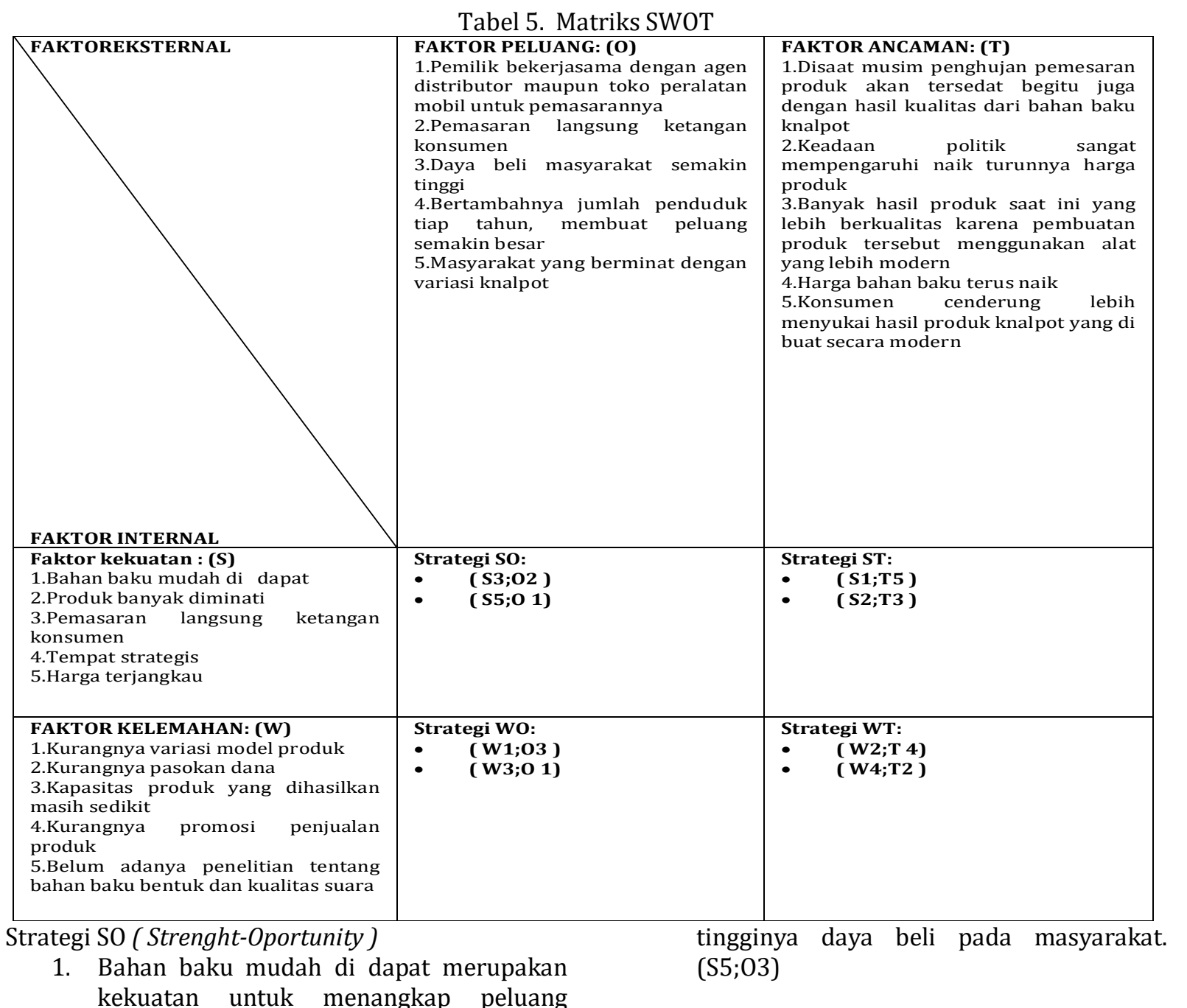
pemilik berkerjasama dengan agen distributor maupun toko peralatan mobil untuk pemasarannya ( $\mathrm{S} 1 ; 01)$.

2. Produk banyak diminati merupakan kekuatan yang diharapkan mampu untuk menangkap peluang masyarakat yang berminat dengan variasi knalpot ( $22 ; 05$ ).

3. Pemasaran langsung ketangan konsumen merupakan kekuatan untuk menangkap peluang yang juga pemasarannya secara langsung. (S3;02).

4. Tempat strategis merupakan kekuatan untuk menangkap peluang bertambahnya jumlah penduduk tiap tahun. (S4;04).

5. Harga terjangkau merupakan kekuatan untuk menangkap peluang semakin

Strategi WO (Weakness-Oppurtiniy) :

1. Menambah variasi model produk untuk menangkap peluang masyarakat yang berminat dengan variasi knalpot. (W1;05).

2. Menambah pasokan dana untuk menangkap peluang bertambahnya jumlah penduduk tiap tahun. (W2;04).

3. Menambah kapasitas produk untuk menangkap peluang pemilik berkerjasama dengan agen distributor maupun toko peralatan mobil untuk pemasarannya. (W3;01).

4. Meningkatkan promosi penjualan produk untuk menagkap peluang (W4;03).

5. Melakukan penelitian tentang bahan baku bentuk dan kualitas suara (W5;02) 
Strategi ST ( Strenght-Threat) :

1. Pemilik bekerjasama dengan agen distributor maupun toko peralatan mobil untuk pemasarannya.

2. Pemasaran langsung ketangan konsumen.

3. Kualitas produk ditingkatkan.

4. Menambah ceruk pasar, membuat peluang semakin besar.

5. Masyarakat yang berminat dengan ragam variasi knalpot.

Strategi WT ( weakness-Threat):

1. Meningkatkan pemasaran produk yang tersendat dengan peningkatan kualitas bahan baku knalpot.

2. Mempertimbangkan kondisi politik yang sangat mempengaruhi naik turunnya harga produk.

3. Membuat produk yang menarik meski menggunakan alat yang lebih sederhana.

4. Mempertahankan pemasok bahan baku.

\section{MATRIKS IE}

Matriks Internal Eksternal (IE) adalah sebuah model identifikasi posisi perusahaan yang dikembangkan berdasarkan model General Electric. Model ini digunakan adalah untuk mengidentifikasi strategi bisnis yang lebih detail di tingkat korporasi. Melalui identifikasi pada 9 sel strategi perusahaan, menurut Rangkuti (2001), kesembilan sel itu pada prinsipnya dapat dikelompokkan menjadi 3 (tiga) strategi utama, yaitu:

1. Growth strategy.

2. Stability strategy.

3. Retrencment strategy.

Analisis Matriks IE digunakan untuk mengetahui posisi PT. X saat ini. Matriks IE didasarkan pada nilai tertimbang yang diperoleh pada matriks IFE dan EFE. Nilai tertimbang sebesar 2,75 diperoleh dari matriks IFE, sedangkan matriks EFE menghasilkan nilai tertimbang sebesar 2,20 . Melalui nilai tertimbang dalam matriks IFE dan EFE dapat diketahui posisi PT. X pada kuadran seperti gambar berikut ini:

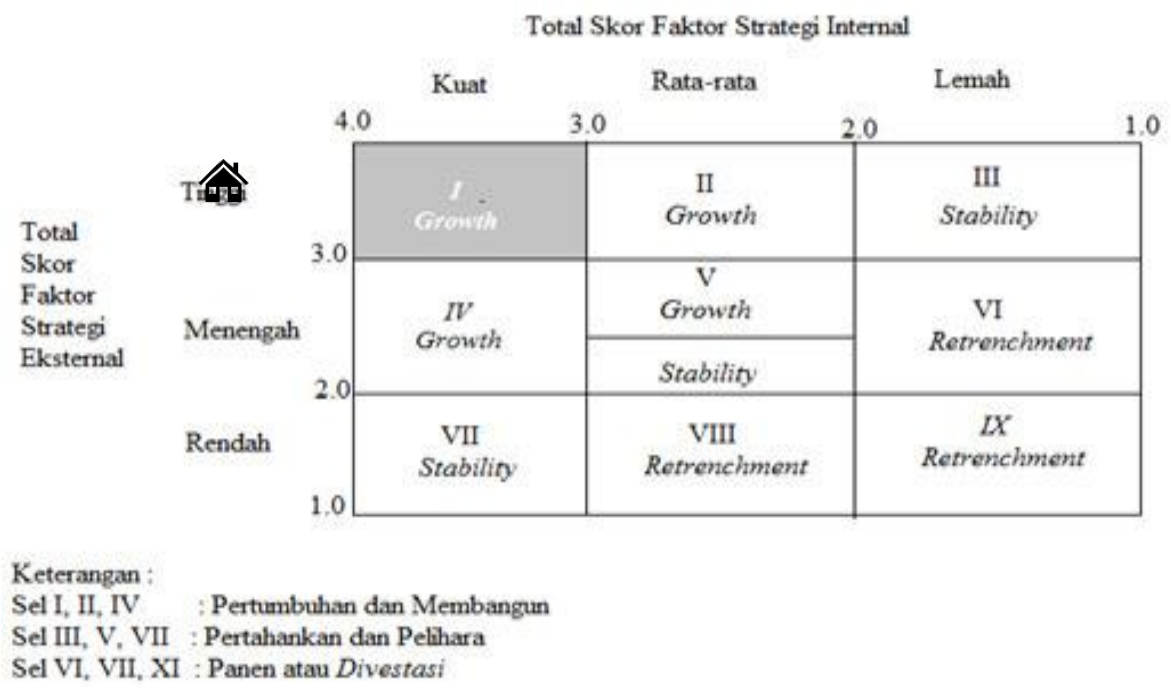

Gambar 2. Posisi PT.X pada Matriks IE

Gambar diatas menunjukkan posisi PT. X pada posisi sel V (Growth) yang menunjukan perusahaan tersebut berada pada posisi dengan strategi pertahankan dan pelihara.

Dari matriks SWOT sebelumnya didapatkan beberapa strategi yang sesuai dengan posisi kuadran $\mathrm{V}$ tersebut adalah sebagai berikut:

- Mempertahankan posisi pemasok dan pemasar (strategi S01, S03, WT2, WT4)

- Menambah variasi model dengan harga terjangkau (SO2, SO5, W01, W05, ST3, ST5, WT3)
- Menentukan lokasi strategis untuk distribusi dan pemasaran (SO4, WO4, ST1, ST2, ST4)

- Menambah investasi (W02, W03, WT1)

\section{MATRIKS CPM}

Matriks CPM memberikan informasi penting pada perusahaan tentang posisi pesaingpesaing yang ada disekitar perusahaan, yaitu dengan mengetahui seberapa tinggi nilai bobot perusahaan terhadap pesaing lainnya, Dalam matriks CPM, peringkat dan total nilai tertimbang 
untuk PT. X dapat dibandingkan dengan pesaingpesaing yang ada.

Tabel 6 dibawah ini memberikan informasi tingkat nilai bobot yang dihitung serta hasil rating tiap-tiap pesaing PT. X yang ada.

Tabel 6. Analisa Matriks CPM pada PT. X

\begin{tabular}{|c|c|c|c|c|c|c|c|}
\hline & \multirow{2}{*}{ Bobot } & \multicolumn{2}{|c|}{ Knalpot PT.X } & \multicolumn{2}{|c|}{ Perusahaan A } & \multicolumn{2}{|c|}{ Perusahaan B } \\
\hline & & Rating & Skor & Rating & Skor & Rating & Skor \\
\hline Harga & 0,20 & 3 & 0,62 & 4 & 0,80 & 4 & 0,74 \\
\hline Mutu produk & 0,19 & 3 & 0,60 & 3 & 0,59 & 3 & 0,64 \\
\hline Varian model & 0,20 & 4 & 0,83 & 3 & 0,63 & 4 & 0,88 \\
\hline Kualitas produk & 0,22 & 3 & 0,64 & 3 & 0,65 & 3 & 0,65 \\
\hline $\begin{array}{l}\text { Promosi } \\
\text { penjualan }\end{array}$ & 0,19 & 3 & 0,57 & 3 & 0,60 & 3 & 0,60 \\
\hline Total & 1,00 & & 3,27 & & 3,28 & & 3,51 \\
\hline
\end{tabular}

Dari kriteria-kriteria penentu keberhasilan yang sudah dijabarkan diatas, yang berdasarkan nilai bobot faktor kriteria IFE dan EFE serta dari hasil observasi terhadap faktor penentu keberahasilan yang dimiliki pesaing-pesaing PT.X, dapat diketahui bahwa bobot tertinggi pada faktor penentu keberhasilan adalah factor kualitas produk, dengan bobot tertinggi sebesar 0,22. Dari ketiga profil pesaing yang telah diidentifikasi, menunjukkan bahwa Perusahaan B merupakan pesaing utama dengan nilai skor tertinggi sebesar 3,51 dan PT. X sendiri dengan nilai skor terendah sebesar 3,27. Terdapat selisih sebesar 0,24 yang berarti harus ada usaha ekstra untuk menyamai kondisi perusahaan pesaing B agar PT. X tetap bisa bersaing, atau bahkan melampauinya.

Maka dari strategi pertahankan dan pelihara yang telah ditentukan sebelumnya dapat ditentukan prioritas dan target yang harus dicapai adalah sebagai berikut:

- Meningkatkan kualitas dan variasi produk dengan harga terjangkau

- Meningkatkan kapasitas produksi dan promosi penjualan

\section{PENUTUP}

Berdasarkan hasil pengamatan, pengolahan dan analisa data dapat disimpulkan sebagai berikut :

1. Strategi di PT. X dapat disusun dengan metode SWOT, dan ditunjang dengan pendekatan manajemen strategi.

2. Strategi yang dihasilkan dengan melihat kemampuan perusahaan adalah strategi pertahankan dan pelihara. Dimana dengan mempertimbangkan posisi perusahaan dan pesaingnya, didapatkan strategi yang sesuai adalah sebagai berikut : a. Meningkatkan kualitas dan variasi 1produk dengan harga terjangkau

b. Meningkatkan kapasitas produksi dan promosi penjualan

Berikut ini adalah saran - saran yang dapat diberikan kepada PT. X dan penelitian berikutnya :

1. PT. $X$ sebaiknya meningkatkan kualitas produk, mulai bahan baku hingga produk jadi. Demikian juga PT. X sebaiknya meningkatkan program promosi yang telah ada agar lebih intensif dan efektif dengan media teknologi informasi. Mengganti iklan spanduk yang telah iu0975 usang dengan iklan baru yang lebih menarik perhatian konsumen.

2. Variablel-variabel dalam penelitian ini masih sedikit jumlahnya, makan diharapkan penelitian selanjutnya akan menggunakan variable yang lebih banyak dan lebih beragam.

\section{DAFTAR PUSTAKA}

David, F. R. (2006). Strategic Management (Manajemen Strategis). Salemba Empat, Jakarta.

Deswita, E. (2008). Analisis Strategi Bersaing Jasa Konsultan pada PT Sanjungan Consultant di Bandarlampung.

Kotler, P., \& Keller, K. L. (2009). Manajemen Pemasaran (judul asli: Marketing Management), edisi ketiga belas, jilid 1 . Penerjemah Bob Sabran. Jakarta: Erlangga.

Mufidatun, B. (2005). Strategi Bersaing pada Bauran Pemasaran PT Sunan Drajat Lamongan.

Rangkuti, F. (2001). Analisis SWOT Teknik Membelah Kasus Bisnis.

Supranoto, M. (2009). Strategi menciptakan keunggulan Bersaing produk melalui orientasi pasar, Inovasi, dan orientasi kewirausahaan Dalam rangka meningkatkan kinerja Pemasaran (Studi empiris pada: Industri Pakaian Jadi Skala Kecil dan Menengah di kota Semarang). UNIVERSITAS DIPONEGORO. 